\title{
Internal Standards for Quantitative Analysis of Chemical Warfare Agents by the GC/MS Method: Nerve Agents
}

\author{
Tomas Capoun (iD and Jana Krykorkova \\ Ministry of Interior-Directorate General of the Fire Rescue Service CR, Population Protection Institute, Na Luzci 204, \\ Lazne Bohdanec 533 41, Czech Republic
}

Correspondence should be addressed to Tomas Capoun; tomas.capoun@ioolb.izscr.cz

Received 30 April 2020; Accepted 23 July 2020; Published 11 August 2020

Academic Editor: Ricardo Jorgensen Cassella

Copyright (c) 2020 Tomas Capoun and Jana Krykorkova. This is an open access article distributed under the Creative Commons Attribution License, which permits unrestricted use, distribution, and reproduction in any medium, provided the original work is properly cited.

\begin{abstract}
General conditions and requirements for an internal standard useful in the determination of chemical warfare agents (CWAs) by the method of gas chromatography coupled with mass detection (GC/MS) were defined. The determination is based on a GC/MS analysis of a mixture of a CWA with an internal standard, conversion of the TIC chromatogram to a chromatogram extracted at a particular $\mathrm{m} / \mathrm{z}$ ratio, and calculation of the CWA concentration from the internal standard concentration, response factor, and chromatographic peak areas. Available internal standards were identified, and they were verified for seven organophosphorus nerve-paralysing agents. Corresponding response factors were determined as a ratio of gradients of the linear functions of the peak area and compound concentration. Linearity, repeatability, and accuracy of the measurements were evaluated. The determination can be performed on all GC/MS systems of the Fire Rescue Service of the Czech Republic (FRS), where no CWA standards are available.
\end{abstract}

\section{Introduction}

According to the Czech Republic law, competences of the FRS include chemical countermeasures in case of CWA spills or abuse. The countermeasures include chemical reconnaissance, detection, identification, and determination of CWAs. This activity is ensured by specialized FRS chemical laboratories. All laboratories are equipped by gas chromatography with mass detection (GC/MS) as most frequent analytical systems. Three types of systems are used in the FRS: GC/MS 7890A/5975 (Agilent), GC/MS Intuvo 9000/ 5977B of the same manufacturer, and EM 640 (Bruker Daltonik). Usually, quantitative analysis is performed by the absolute calibration method on these machines, but only for those analytes where a standard of corresponding purity is available.

The fundamental issue is that pure and certified CWA standards are not available in the Czech Republic. Therefore, we had to turn our attention to a procedure based on an internal standard, i.e., addition of a known amount of a substance different from the analyte into the sample, to determine these substances. This method is based on the fact that within a certain concentration range, the ratio of chromatographic peak areas and concentrations is constant. This ratio is called the response or calibration factor [1]:

$$
\mathbf{F}_{\mathbf{R}}=\frac{\mathbf{A} \text { CWA } / \mathbf{c} \text { CWA }}{\mathbf{A} \text { ISTD } / \mathbf{c} \text { ISTD }}=\frac{\mathbf{A} \text { CWA } \cdot \mathbf{c} \text { ISTD }}{\text { A ISTD } \cdot \mathbf{c} \text { CWA }},
$$

where $\mathbf{F}_{\mathbf{R}}$ is the response factor, $\mathbf{A}_{\mathrm{CWA}}$ is the CWA chromatographic peak area, $\mathbf{A}_{\text {ISTD }}$ is internal standard chromatographic peak area, $\mathbf{c}_{\mathrm{CWA}}$ is the CWA concentration in the solution, and $\mathbf{c}_{\text {ISTD }}$ is internal standard concentration in the solution.

The internal standard method has several significant advantages. Unlike the absolute calibration and standard addition methods, pure analyte standard is not required. The absolute calibration and standard addition methods include analysis of two separate samples which often introduces significant errors into the results $[1,2]$. The same applies to the external standard method. 
When using the internal standard method, the response factor value needs to be known in order to arrive at reliable analytical results. Additionally, the concentration range where the analyte and internal standard chromatographic peak area is a linear function must be known, as only then, the constant value of the response factor is ensured [1, 3]. This explains why many articles focusing on internal standard applications begin by a detailed validation, especially testing linearity of the function and the limit of quantification and repeatability of the analysis [4-16]. In case the sample is modified before the analysis (extraction, distillation, and solvent evaporation), maximum similarity of chemical and physical characteristics of the analyte and of the internal standard should be ensured [1, 3]. Close retention times of the analyte and the internal standard are also required in order to eliminate peak area discrimination at varying temperatures under temperature-programmed conditions $[1,3]$. On top of these published requirements for the internal standard selection, one needs to consider the requirement that the internal standard must neither react or interact with the analyte nor constitute a decomposition product or other admixture of the analysed compounds.

For use in quantitative GC/MS analysis, the most efficient and reliable solution is the use of such internal standard which is identical or analogous to the analyte and labelled by a stable isotope [1, 17]. Examples include the determination of acrylamide in wheat samples, using [13C3]-acrylamide [18], determination of chrysene in a foil using [2H12]-chrysene [19], determination of rotundone in grapes and wine by the SPME method using [2H5]rotundone [2], and determination of ethyl carbamate using [2H5]-ethyl carbamate, also in wine [9]. Additional examples include the use of [2H8]-dibenzothiophene for the determination of dibenzothiophene in crude oil, coal, and sediment extracts [20], [2H7]-meprobamate for the determination of meprobamate in blood [13], [13C12]-triclosane for the determination of triclosane in water [21], or [13C]dichlorodiphenyltrichloroethane for the determination of dichlorodiphenyltrichloroethane (DDT) in the air [16]. However, internal standards labelled by a stable isotope are also used for samples where compounds other than analogues of the standard are analysed. For the determination of a number of hydrocarbons and other volatile compounds in internal or external air, [2H6]-benzene [11], [2H8]-toluene $[22,23]$ or [2H10]-ethylbenzene are used as internal standards. Similarly, some deuterized components of gasoline were used for the determination of aliphatic and aromatic hydrocarbons in water by the SPME method [7]. Additional examples of the internal standard use are [2H4]-1,2-dichloroethane for the determination of 26 halogenated compounds in water [24], [2H5]-3,4-methylenedioxyamphetamine and [2H6]-hydromorphone for the determination of narcotics and their metabolites in biological samples [4], and [2H14]-trifluarine, [2H6]-transpermethrine, and [2H4]-nitrophenol for the determination of 28 pesticides in the air [25]. This makes labelled analyte analogues ideal as internal standards for the determination of compounds by the GC/MS methods; however, their disadvantage is poor availability and high price.
When the internal standard differs from the analyte, compound losses during various phases of sample preparation unavoidably differ [1]. These differences can be efficiently minimized by the use of double internal standards, when two neighbouring representatives from the homologous series are used as internal standards for the determination of a specific agent $[1,19]$. Further examples include determination of tocopherol in plasma, where pentamethylchromanol was used as the internal standard [6], determination of 2,5-di-tert-butyl-3-methylphenol in chewing gums using 3,5-di-tert-butylphenol [26], determination of furaneol in tomatoes using maltol [27], or determination of carisoprodole in blood using benzyl carbamate [13]. Anisole was used for the determination of various air contaminants [28]. In the analysis of food industry raw materials and products, 5-nonanone was used for the determination of 34 different chemical compounds in honey by the dynamic headspace method [5, 27], dinonyl phthalate for the determination of policosanol components extracted from rice bran wax [29], octyl acetate for the determination of 35 volatile compounds in essential oils obtained by steam distillation of lemon tree leaves and bark [30], and crotonic acid for the determination of volatile fatty acids in cheeses after steam distillation [31]. In water analysis, fluorobenzene was used as the internal standard for the determination of trihalomethanes by the GC/MS method using SPME [32] and benzyl benzoate for the determination of phthalates using the same method [33]. In the analysis of industrial products, diphenyl ether was used for the determination of lactide monomer in polylactic materials [34], 1,2-dichlorobenzene was used for the determination volatiles in water-oil emulsion by the SPME method [35], and tetrabromodiphenyl ether was used for the analysis of fire retarders on the basis of polybrominated diphenyl ethers, organophosphates, and brominated aromatic hydrocarbons [15].

This work focuses on the determination of CWAs by the GC/MS method. Only few sources discussing internal standards for this purpose could be identified. Dipinacolyl methyl phosphonate was described as an internal standard for the determination of tabun, cyclosarin, the VX agent, and nitrogen mustard [8]. The TNO laboratory in Rijswijk, the Netherlands, focusing especially on the CWA analysis, uses deuterized sulphur mustard, [2H8]-bis-(2-chloroethyl)sulphide, as internal standard for the determination of sulphur mustard [36].

When applying the internal standard, it is always necessary to evaluate the intensity of the analyte and standard chromatographic peaks. The TIC area is usually considered [1]. More precise results can be achieved when considering the peak area of a particular ion $[2,4]$, although the TIC area of the chromatographic peak can be sometimes more useful [5]. This is discussed in detail in publication [4].

This work focuses on a search for an available standard which would fulfill the requirement of matching CWA and internal standard response ratios on all GC/MS systems in the FRS laboratories. The aim of the work was to develop a procedure for the FRS laboratories which would not only allow for the determination of CWAs in solutions, but could 
be also used for a fast and simple determination of the active substance in the CWA preparates themselves. These preparates are further used for the calibration of the existing internal procedures for the determination of CWA, mostly by photometric and biochemical methods.

\section{Materials and Methods}

2.1. Chemicals. The quantitative analyses procedures by the GC/MS method were developed for the following CWAs: O-ethyl-N,N-dimethylphosphoramidocyanidate (tabun, GA, $88 \%$ ), O-isopropylmethylphosphonofluoridate (sarin, GB, 64\%), O-(3,3-dimethyl-2-butyl)methylphosphonofluoridate (soman, GD, 79\%), O-cyclohexylmethylphosphonofluoridate (cyclosarin GF, 58\%), O-ethyl-S-(diisopropylaminoethyl) methylphosphonothioate (VX agent, 69\%), O-ethyl-S(diethylaminoethyl)methylphosphonothioate (Edemo, 51\%), and O-ethyl-S-(dimethylaminoethyl)methylphosphonothioate (Medemo, 24\%). All compounds were prepared in VOZ Zemianské Kostolany, Slovakia. Tabun assay was determined by potentiometric argentometric titration of cyanides by silver nitrate indicated by a silver electrode; assay of sarin, soman, and cyclosarin was determined by potentiometric lanthanometric titration of fluorides by lanthanum (III) chloride indicated by a fluoride ion selective electrode; assay of the VX agent, Edemo, and Medemo compounds was determined by potentiometric argentometric titration of thiols by silver nitrate indicated by a sulphide ion selective electrode.

Triethylphosphate (99.8+\%, Sigma-Aldrich), heptan-1ol (>99\%, Fluka), tri-n-butylphosphate (p.a., Merck), di-nhexylamine (p.a., Merck), and di-n-amylether (p.a., Merck) were the internal standards used. Solutions of CWAs and internal standards were prepared in acetone or n-hexane (SupraSolv, for GC, Merck).

2.2. Measurement Conditions and Parameters. The measurements were performed on the following systems at conditions and parameters listed in Table 1. System A-GC/ MS 7890A/5975C (Agilent Technologies, Inc., Wilmington, USA); system B-GC/MS Intuvo 9000/5977B same manufacturer; and system C-mobile GC/MS EM 640 (Bruker Daltonik GmbH, Bremen, Germany).

Solutions of CWAs and internal standard were mixed in a $1: 1(v / v)$ ratio, and the mixture was introduced into the injection inlet of the GC/MS system. The linearity range of the chromatographic peak area as a function of the compound concentration was studied in parallel both for the CWA and the corresponding internal standard. Hence, mixtures of CWAs and standards of the same concentration were injected. Triplicate measurements were performed for each concentration of the compound and the standard.

2.3. Chromatogram Evaluation. Peaks corresponding to the CWA and the internal standard were identified in the TIC chromatogram recorded in the scan mode. The peak area was obtained by integration using the evaluation software listed in Table 1. Generally, automatic integration was used, and only tailing peaks were integrated manually. For further study, EIC chromatograms at a particular $m / z$ ratio were extracted from the TIC chromatograms; peak areas corresponding to the CWAs and the internal standards were obtained by an identical procedure.

In order to assess the dependency of the chromatographic peak area on the concentration of the given compound in the solution, calibration curves were constructed. The linearity range was determined using statistical software [37] based on the correlation coefficient $R$ and coefficient QC values. Coefficient values of $R_{\mathrm{CRIT}} 0.99$ and $\mathrm{QC}_{\mathrm{CRIT}} 5.00$ were considered as critical for the testing. The gradient, $y$ range, and standard deviation of the gradient and range were evaluated by software [37] in the identified linearity range.

In order to assess the accuracy of CWA determination, a series of results from parallel determinations was compared to the known concentration. The $t$-test was used for statistical evaluation [37], comparing the value of $t$ criteria to the critical value. Based on the results from the parallel measurement, the precision of the determination was tested. The method of concentration levels from parallel measurements and calculation of relative standard deviation was selected for the statistical evaluation [37].

\section{Results and Discussion}

3.1. Study of Chromatographic Peak Area Dependence on Concentration. The primary aim of this work was to find a suitable internal standard, applicable on all GC/MS systems across the FRS chemical laboratories in a universal procedure. The procedure would be used especially for a quick and simple determination of the active ingredient of own CWA preparates which are then used for the calibration of the existing determination procedures. This means a binary mixture of the CWA and the internal standard is analysed, and hence, neither similarity of chemical properties of the analyte and the internal standard nor close physical characteristics are an issue here as these matter mostly in case of sample preparation before the analysis itself. On the other hand, this requires highly reliable determination which is closely related to the linearity of the chromatographic peak area as a function of the compound concentration.

Assuming a linear function of the chromatographic peak area and concentration, the relation can be described by the following equation:

$$
\mathbf{A}=\mathbf{k} \cdot \mathbf{c}+\mathbf{q}
$$

where $\mathbf{A}$ is the chromatographic peak area, $\mathbf{k}$ is the gradient, $\mathbf{c}$ is concentration, and $\mathbf{q}$ is the intercept on the peak area axis. This equation can be combined with the response factor equation (1):

$$
\mathbf{F}_{\mathbf{R}}=\frac{(\mathbf{k C W A} \cdot \mathbf{c} \mathrm{CWA}+\mathbf{q} \mathrm{CWA}) \cdot \mathbf{c I S T D}}{(\mathbf{k I S T D} \cdot \mathbf{c I S T D}+\mathbf{q} \mathrm{ISTD}) \cdot \mathbf{c C W A}}
$$

Assuming that the intercept on the peak area is negligible compared to the product of gradient and concentration, i.e., the linear function of CWA and internal standard peak area and concentration passes through the origin, the response 
TABLE 1: Measurement conditions and parameters.

\begin{tabular}{|c|c|c|c|}
\hline GC/MS & $7890 \mathrm{~A} / 5975 \mathrm{C}$ & Intuvo $9000 / 5977 \mathrm{~B}$ & EM 640 \\
\hline Column & HP-5MS $30 \mathrm{~m} \times 0.25 \mathrm{~mm}, 0.25 \mu \mathrm{m}$ & HP-5MS $30 \mathrm{~m} \times 0.25 \mathrm{~mm}, 0.25 \mu \mathrm{m}$ & HP-5MS $25 \mathrm{~m} \times 0.35$ \\
\hline Carrier gas & Helium, $147 \mathrm{kPa}$ constant pressure & Helium, $1.2 \mathrm{~mL} / \mathrm{min}$ constant flow & Nitrogen, $500 \mathrm{hPa}$ const \\
\hline Sampler & Agilent GC 80 & Agilent $7693 \mathrm{~A}$ & - \\
\hline Injection & $1 \mu \mathrm{l}$ & $1 \mu 1$ & $1 \mu \mathrm{l}$ \\
\hline Inlet & $\begin{array}{c}290^{\circ} \mathrm{C} \text {, splitless mode, purge flow } \\
100 \mathrm{~mL} / \mathrm{min} \text { at } 2 \mathrm{~min}\end{array}$ & $\begin{array}{r}290^{\circ} \mathrm{C} \text {, splitless mode, } \mathrm{F} \\
100 \mathrm{~mL} / \mathrm{min} \text { at } 2\end{array}$ & $\begin{array}{c}230^{\circ} \mathrm{C} \text {, splitless mode, purge flow } \\
30 \mathrm{~mL} / \mathrm{min} \text { at } 1 \mathrm{~min}\end{array}$ \\
\hline Oven & $\begin{array}{c}40^{\circ} \mathrm{C}(2 \mathrm{~min}), 10^{\circ} \mathrm{C} / \mathrm{min} \text { to } 280^{\circ} \mathrm{C} \\
(10 \mathrm{~min})\end{array}$ & $\begin{array}{c}40^{\circ} \mathrm{C}(2 \mathrm{~min}), 10^{\circ} \mathrm{C} / \mathrm{min} \text { to } 280^{\circ} \mathrm{C} \\
(10 \mathrm{~min})\end{array}$ & $\begin{array}{c}40^{\circ} \mathrm{C}(2 \mathrm{~min}), 10^{\circ} \mathrm{C} / \mathrm{min} \text { to } 280^{\circ} \mathrm{C} \\
(10 \mathrm{~min})\end{array}$ \\
\hline Detector & $\begin{array}{l}\text { Quadrupole } \mathrm{MS}, \mathrm{EI} \text {, scan mode, } \\
\text { transfer line } 290^{\circ} \mathrm{C} \text {, scan range } \\
35-600 \mathrm{amu} \text {, solvent delay } 6 \mathrm{~min}\end{array}$ & $\begin{array}{l}\text { Quadrupole } \mathrm{MS}, \mathrm{EI} \text {, scan mode, } \\
\text { transfer line } 290^{\circ} \mathrm{C} \text {, scan range } \\
35-600 \mathrm{amu} \text {, solvent delay } 6 \mathrm{~min}\end{array}$ & $\begin{array}{l}\text { Quadrupole } \mathrm{MS}, \mathrm{EI}, \text { scan mode, } \\
\text { transfer line } 280^{\circ} \mathrm{C} \text {, scan range } \\
50-550 \mathrm{amu} \text {, solvent delay } 6 \mathrm{~min}\end{array}$ \\
\hline $\begin{array}{l}\text { Evaluation of } \\
\text { chromatograms }\end{array}$ & $\begin{array}{l}\text { Agilent chemstation GC/MSD_data } \\
\text { analysis, version E.02.02., Agilent } \\
\text { Technologies, Inc., } 2011\end{array}$ & $\begin{array}{c}\text { MassHunter Workstation software, } \\
\text { version B.07.00, Agilent } \\
\text { Technologies, Inc., } 2014\end{array}$ & $\begin{array}{l}\text { Bruker Data Analysis, version 1.1., } \\
\text { Bruker Daltonik GmbH, } 2003\end{array}$ \\
\hline
\end{tabular}

factor equals the ratio of gradients of the two linear functions of CWA and the internal standard peak area and concentration:

$$
\mathbf{F}_{\mathbf{R}}=\frac{\mathbf{k} \text { CWA }}{\mathbf{k} \text { ISTD }}
$$

Use of equation (4) for the determination of the response factor has two fundamental prerequisites. First, the intercepts on the peak area axis must be negligible compared to the product of the gradient and lower limit of the linearity range both for the CWA and for the internal standard. We have set the intercept must be lower than $10 \%$ of the product of gradient and the lowest useful concentration. Second, the response factor can only be applied in the concentration range where the function of CWA and the internal standard peak area is linear. The determination method was developed for the different GC/MS systems whose linearity ranges significantly differ. Moreover, the linearity range also depends on the analyte. Yet, linearity of the response greatly influences reliability of the determination. A typical example is illustrated in Figure 1 showing the chromatographic peak area of cyclosarin as a function of its concentration in the solution.

A number of potential compounds were tested during the search for suitable internal standards. Both TIC chromatograms and EIC chromatograms extracted for a characteristic ion $m / z$ were evaluated. We have found that the calculation of the response factor from the TIC chromatograms recorded in scan mode is not suitable. Only few standards with an identical response factor across the tested systems could be found; most standards exhibited high differences between the systems. Moreover, a reproducible linear calibration curve could not be constructed at all for some of the compounds even in a narrow concentration range. In some cases, the requirement of a negligible intercept on the peak area axis versus the product of gradient and concentration was not met.

The use of EIC chromatogram, extracted both for the CWA and the internal standard at a particular $\mathrm{m} / z$ value, is the optimal procedure for CWAs determination using the internal standard method. This implies that an internal standard exhibiting an intense peak corresponding to the same ion as for the CWA mass spectrum has to be identified.
In turn, this allows for a wider linearity range with the EIC chromatograms than with the TIC chromatograms. Moreover, the EIC chromatograms of the CWAs and the identified standards meet the negligible intercept requirement more easily. Reproducibility of the peak area readings is much higher for the EIC chromatograms than for the TIC chromatograms. Moreover, the EIC chromatogram peak area reading is more robust and resistant to interference with compounds with similar retention times than with the use of TIC chromatograms.

3.2. Determination of Tabun. The $m / z$ values of $43,70,44$, 133 , and 162 dominate the mass spectrum. Methyllaurate $(\mathrm{m} / z 43)$ and crotonaldehyde $(\mathrm{m} / z$ 70) were tested as the available chemicals for the internal standard. However, the response factors highly varied across the GC/MS systems (the $\mathbf{F}_{\mathbf{R}}$ values of methyllaurate $\mathrm{m} / z 43$ reached $0.75,0.27$, and 1.02 for systems $A, B$, and $C$, respectively; for crotonaldehyde $m / z 70$, the values reached $0.64,0.49$, and 1.14 for systems $A, B$, and $C$, respectively). Although satisfactory results could be obtained when using dihexylamine at $\mathrm{m} / z 43$ as the internal standard, we found out that as a weak base, dihexylamine causes the decomposition of tabun after a certain period of time, giving rise to O-ethyl-O-methyl N,Ndimethylamidophosphate. Hence, dihexylamine does not fulfill the requirement that the internal standard must not react with the analyte. Best results were achieved with heptan-1-ol at $m / z 70$, as shown in Table 2. For simplicity, chromatographic peak area values are given in millions of abundance units in all following tables.

3.3. Determination of Sarin, Soman, and Cyclosarin. Other type G-type nerve-paralysing agents exhibit the $\mathrm{m} / z$ 99 as one of the most prominent mass spectrum peaks. This fact has led us to the selection of triethylphosphate as a suitable internal standard. The calculated response factor was identical across the three systems tested, as shown in the evaluation in Tables 3-5. The molecule of soman (Table 4) contains two asymmetric atoms, namely, phosphorus and carbon in the pinacolyl group, and forms four stereoisomers 


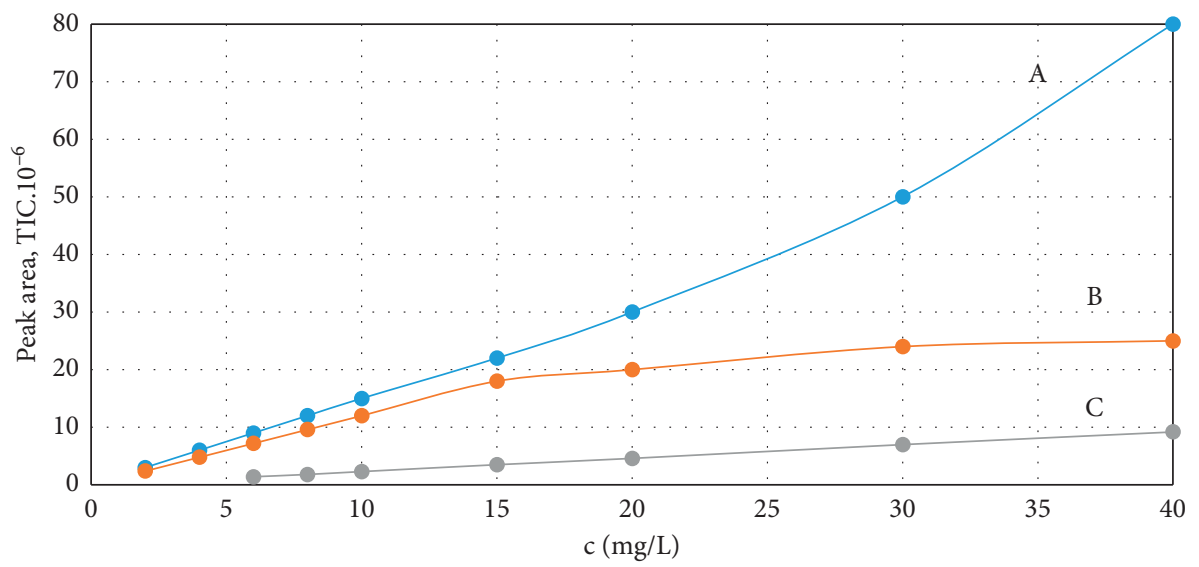

FIGURE 1: TIC chromatographic peak area of cyclosarin as a function of its concentration in the solution, measured at the following GC/MS systems: 7890A/5975C (A), intuvo 9000/5977B (B), and EM 640 (C).

TABLE 2: Evaluation of the chromatographic peak area of tabun and heptan-1-ol at $m / z 70$ as a linear function of their concentration (critical values of the correlation coefficient $\mathbf{R}_{\mathrm{CRIT}} 0.99$ and QC coefficient $\mathrm{QC}_{\mathrm{CRIT}} 5.00$ ).

\begin{tabular}{|c|c|c|c|c|c|c|}
\hline \multirow{2}{*}{ GC/MS compound } & \multicolumn{2}{|c|}{$7890 \mathrm{~A} / 5975 \mathrm{C}$} & \multicolumn{2}{|c|}{ Intuvo $9000 / 5977 \mathrm{~B}$} & \multicolumn{2}{|c|}{ EM 640} \\
\hline & Tabun & Heptanol & Tabun & Heptanol & Tabun & Heptanol \\
\hline Retention time (min) & 13.3 & 10.4 & 10.3 & 7.8 & 12.6 & 9.8 \\
\hline Linearity range $(\mathrm{mg} / \mathrm{L})$ & $2.5-40$ & $2.5-40$ & $0.5-10$ & $0.5-10$ & $10-50$ & $10-50$ \\
\hline $\mathbf{R}$ & 0.9988 & 0.9994 & 0.9999 & 0.9968 & 0.9999 & 0.9996 \\
\hline QC & 3.28 & 2.56 & 0.86 & 4.13 & 0.21 & 1.49 \\
\hline Gradient $\left(A \times 10^{-6} \times \mathrm{L} / \mathrm{mg}\right)$ & 0.71 & 1.4 & 0.13 & 0.25 & 0.015 & 0.032 \\
\hline Intercept $\left(A \times 10^{-6}\right)$ & 0.065 & -0.34 & -0.0030 & -0.0090 & 0.00012 & -0.015 \\
\hline Response factor $\mathbf{F}_{\mathbf{R}}$ & \multirow{2}{*}{\multicolumn{2}{|c|}{0.49}} & \multirow{2}{*}{\multicolumn{2}{|c|}{$\begin{array}{c}0.52 \\
0.50\end{array}$}} & \multirow{2}{*}{\multicolumn{2}{|c|}{0.48}} \\
\hline Average value of $\mathbf{F}_{R}$ & & & & & & \\
\hline
\end{tabular}

[38] giving rise to two chromatographic peaks. Examples are shown in Figure 2. The total area is a sum of both peak areas.

3.4. Determination of the VX Agent. The VX agent exhibits a dominant peak at $m / z$ ratio 114 and less pronounced peaks at $m / z 72$ and 127 . Tripropylamine $(m / z 114$ and 72$)$ and 3aminohexane $(m / z 72)$ have much shorter retention time at the separation conditions used, compared to the VX agent. Further internal standards tested exhibited significant variances in the agent VX vs. internal standard response across the systems used. We have verified, e.g., m-chloroaniline $\left(\mathbf{F}_{\mathbf{R}}\right.$ value for $m / z 127$ reached $0.12,0.03$, and 0.65 for systems $A, B$, and $C$, respectively), 5-chloro-2-methoxypyrimidine $\left(\mathbf{F}_{\mathbf{R}}\right.$ value for $m / z 114$ reached 1.60, 0.30, and 1.21 for systems $A, B$, and $C$, respectively), 2-chloro-4-methoxypyrimidine $\left(\mathbf{F}_{\mathbf{R}}\right.$ value for $m / z 114$ reached $1.80,0.50$, and 1.42 for systems $A, B$, and $C$, respectively), and dimethyl adipate $\left(\mathbf{F}_{\mathbf{R}}\right.$ value for $\mathrm{m} / z 114$ reached $3.00,1.66$, and 2.07 for systems $A, B$, and $C$, respectively). Very close response factor values across different GC/MS systems could be achieved with dipropyltryptamine at $m / z 114\left(\mathbf{F}_{\mathbf{R}}\right.$ value reached $0.71,0.72$, and 0.73 for systems $A, B$, and $C$, respectively). However, taking into account its problematic nature, dipropyltryptamine was not selected as the internal standard for the VX agent.

Most reliable results could be achieved with di-n-hexylamine at $m / z 114$ as the internal standard. The evaluation is shown in Table 6. Analysis of the mixture of the VX agent and the internal standard must be performed in an apolar solvent. We found out that, in the methanolic environment, agent VX undergoes decomposition due to the presence of the basic amine, and the requirement that the internal standard must neither react with the analyte nor interact in any way is, therefore, not fulfilled. The whole amount of the VX agent was completely decomposed already 6 hours after mixing the methanolic solution of the VX agent and di-nhexylamine in a concentration range $5-50 \mathrm{mg} / \mathrm{L}$. For the analysis in methanolic solution, this implies that the analysed mixture would have to be mixed with the di-n-hexylamine solution immediately before the analysis, which is not advantageous for larger sample sets.

3.5. Determination of Edemo. The Edemo agent exhibits two dominant peaks corresponding to $\mathrm{m} / z$ ratios 86 and 99 . The available compounds tested as internal standards are significantly more volatile than the analyte, and they have significantly shorter retention times: triethylamine $(\mathrm{m} / z \mathrm{86})$, tripropylamine $(\mathrm{m} / \mathrm{z} 86), 2$-(diethylamino)ethan-1-ol $(\mathrm{m} / z$ $86)$, and triethylphosphate $(m / z 99)$. Attention was also paid to N-butylacetamide at $\mathrm{m} / z$ 86; however, although reproducible results with close response factor values across the GC/MS systems could be obtained ( $F_{\mathbf{R}}$ value reached 0.97 , 0.93 , and 0.94 for systems $A, B$, and $C$, respectively), the compound was not selected as the internal standard for Edemo determination due to its high price. Most reliable 
TABLE 3: Evaluation of the chromatographic peak area of sarin and triethylphosphate at $m / z 99$ as a linear function of their concentration (critical values of the correlation coefficient $\mathbf{R}_{\mathrm{CRIT}} 0.99$ and QC coefficient QC $\mathrm{CRIT}$ 5.00).

\begin{tabular}{|c|c|c|c|c|c|c|}
\hline \multirow{2}{*}{ GC/MS compound } & \multicolumn{2}{|c|}{$7890 \mathrm{~A} / 5975 \mathrm{C}$} & \multicolumn{2}{|c|}{ Intuvo $9000 / 5977 \mathrm{~B}$} & \multicolumn{2}{|r|}{ EM 640} \\
\hline & Sarin & Triethyl-phosphate & Sarin & Triethyl-phosphate & Sarin & Triethyl-phosphate \\
\hline Retention time (min) & 7.4 & 13.2 & 5.1 & 11.7 & 7.1 & 13.3 \\
\hline Linearity range $(\mathrm{mg} / \mathrm{L})$ & $1-40$ & $2.5-40$ & $0.5-10$ & $0.5-15$ & $5-40$ & $5-50$ \\
\hline $\mathbf{R}$ & 0.9999 & 0.9986 & 0.9998 & 0.9996 & 0.9979 & 0.9988 \\
\hline QC & 1.07 & 3.68 & 1.74 & 2.22 & 3.84 & 3.71 \\
\hline Gradient $\left(A \times 10^{-6} \times \mathrm{L} / \mathrm{mg}\right)$ & 2.9 & 1.4 & 0.74 & 0.38 & 0.040 & 0.020 \\
\hline Intercept $\left(A \times 10^{-6}\right)$ & 0.18 & -0.24 & -0.030 & 0.014 & 0.0088 & 0.0073 \\
\hline $\begin{array}{l}\text { Response factor } F_{R} \\
\text { Average value of } \mathbf{F}_{R}\end{array}$ & \multicolumn{2}{|c|}{2.06} & & $\begin{array}{l}1.93 \\
1.99\end{array}$ & \multicolumn{2}{|r|}{1.97} \\
\hline
\end{tabular}

TABLE 4: Evaluation of the chromatographic peak area of soman and triethylphosphate at $\mathrm{m} / z$ g9 as a linear function of their concentration (critical values of the correlation coefficient $\mathbf{R}_{\mathrm{CRIT}} 0.99$ and QC coefficient QC $\mathrm{CRIT}_{\mathrm{C}}$ 5.00).

\begin{tabular}{|c|c|c|c|c|c|c|}
\hline \multirow{2}{*}{ GC/MS compound } & \multicolumn{2}{|c|}{$7890 \mathrm{~A} / 5975 \mathrm{C}$} & \multicolumn{2}{|c|}{ Intuvo $9000 / 5977 \mathrm{~B}$} & \multicolumn{2}{|r|}{ EM 640} \\
\hline & Soman & Triethyl-phosphate & Soman & Triethyl-phosphate & Soman & Triethyl-phosphate \\
\hline Retention time (min) & 11.7 & 13.2 & 10.3 & 11.7 & 11.6 & 13.3 \\
\hline Linearity range $(\mathrm{mg} / \mathrm{L})$ & $2.5-20$ & $2.5-40$ & $1-15$ & $0.5-15$ & $5-40$ & $5-50$ \\
\hline $\mathbf{R}$ & 0.9971 & 0.9985 & 0.9991 & 0.9989 & 0.9988 & 0.9978 \\
\hline QC & 4.32 & 3.63 & 3.07 & 3.76 & 3.16 & 4.79 \\
\hline Gradient $\left(A \times 10^{-6} \times \mathrm{L} / \mathrm{mg}\right)$ & 1.6 & 1.4 & 0.45 & 0.39 & 0.024 & 0.021 \\
\hline Intercept $\left(A \times 10^{-6}\right)$ & -0.65 & -0.34 & -0.030 & -0.019 & -0.0019 & 0.010 \\
\hline Response factor $\mathbf{F}_{\mathbf{R}}$ & \multirow{2}{*}{\multicolumn{2}{|c|}{1.10}} & \multirow{2}{*}{\multicolumn{2}{|c|}{$\begin{array}{l}1.16 \\
1.14\end{array}$}} & \multirow{2}{*}{\multicolumn{2}{|c|}{1.16}} \\
\hline Average value of $\mathbf{F}_{R}$ & & & & & & \\
\hline
\end{tabular}

TABLE 5: Evaluation of the chromatographic peak area of cyclosarin and triethylphosphate at $\mathrm{m} / \mathrm{z} 99$ as a linear function of their concentration (critical values of the correlation coefficient $\mathbf{R}_{\text {CRIT }} 0.99$ and QC coefficient QC CRIT 5.00 ).

\begin{tabular}{|c|c|c|c|c|c|c|}
\hline \multirow{2}{*}{ GC/MS compound } & \multicolumn{2}{|c|}{$7890 \mathrm{~A} / 5975 \mathrm{C}$} & \multicolumn{2}{|c|}{ Intuvo $9000 / 5977 \mathrm{~B}$} & \multicolumn{2}{|r|}{ EM 640} \\
\hline & Cyclo-sarin & Triethyl-phosphate & Cyclo-sarin & Triethyl-phosphate & Cyclo-sarin & Triethyl-phosphate \\
\hline Retention time (min) & 14.6 & 13.2 & 12.5 & 11.7 & 14.7 & 13.3 \\
\hline Linearity range $(\mathrm{mg} / \mathrm{L})$ & $5-30$ & $2.5-40$ & $1-12.5$ & $0.5-15$ & $5-50$ & $5-50$ \\
\hline $\mathbf{R}$ & 0.9998 & 0.9992 & 0.9996 & 0.9998 & 0.9969 & 0.9996 \\
\hline QC & 1.62 & 2.82 & 2.01 & 1.28 & 4.45 & 1.68 \\
\hline Gradient $\left(A \times 10^{-6} \times \mathrm{L} / \mathrm{mg}\right)$ & 3.2 & 1.5 & 0.78 & 0.38 & 0.046 & 0.021 \\
\hline Intercept $\left(A \times 10^{-6}\right)$ & -1.3 & -0.29 & 0.0061 & -0.017 & 0.022 & 0.0077 \\
\hline $\begin{array}{l}\text { Response factor } F_{R} \\
\text { Average value of } \mathbf{F}_{\mathbf{R}}\end{array}$ & \multicolumn{2}{|c|}{2.17} & \multicolumn{2}{|c|}{$\begin{array}{l}2.07 \\
2.14\end{array}$} & \multicolumn{2}{|c|}{2.18} \\
\hline
\end{tabular}

results were achieved with tri-n-butylphosphate as the internal standard at $m / z 99$ (Table 7 ).

3.6. Determination of Medemo. As regards to Medemo, as a dimethyl derivative of O-ethyl-S-(dialkylaminoethyl)methylphosphonothioate, the $\mathrm{m} / z$ values 58 and 71 dominate its mass spectrum. Tri-n-octylamine $(\mathrm{m} / z 71)$ was tested as an available compound. However, the linearity range of the chromatographic peak area as a function of concentration was very narrow, rendering the compound practically useless. Response factors of several other compounds tested significantly varied across the GC/MS systems used. We tested, for example, 3-aminohexane $\left(\mathbf{F}_{\mathbf{R}}\right.$ value for $\mathrm{m} / z 58$ reached $0.69,0.34$, and 0.93 for systems $A, B$, and $C$, respectively) or ethylbutyrate $\left(\mathbf{F}_{\mathbf{R}}\right.$ value for $m / z 71$ reached
$0.48,0.18$, and 0.40 for systems $A, B$, and $C$, respectively). Satisfactory results were achieved with di-n-amylether at $m /$ $z 71$ as the internal standard, as shown in Table 8.

3.7. Validation of the Determination. Accuracy and precision of the determination were assessed by method validation. Accuracy was assessed by the statistical $t$-test. Solutions to be analysed were prepared from different CWA batches than those used for the determination of response factors. Five parallel determinations were performed for each solution. The obtained set of concentration determinations was, then, evaluated by statistical software [37] to assess the $t$ criterion which was compared to the critical value. The procedure gives accurate results for $t<t_{\text {CRIT }}$. 


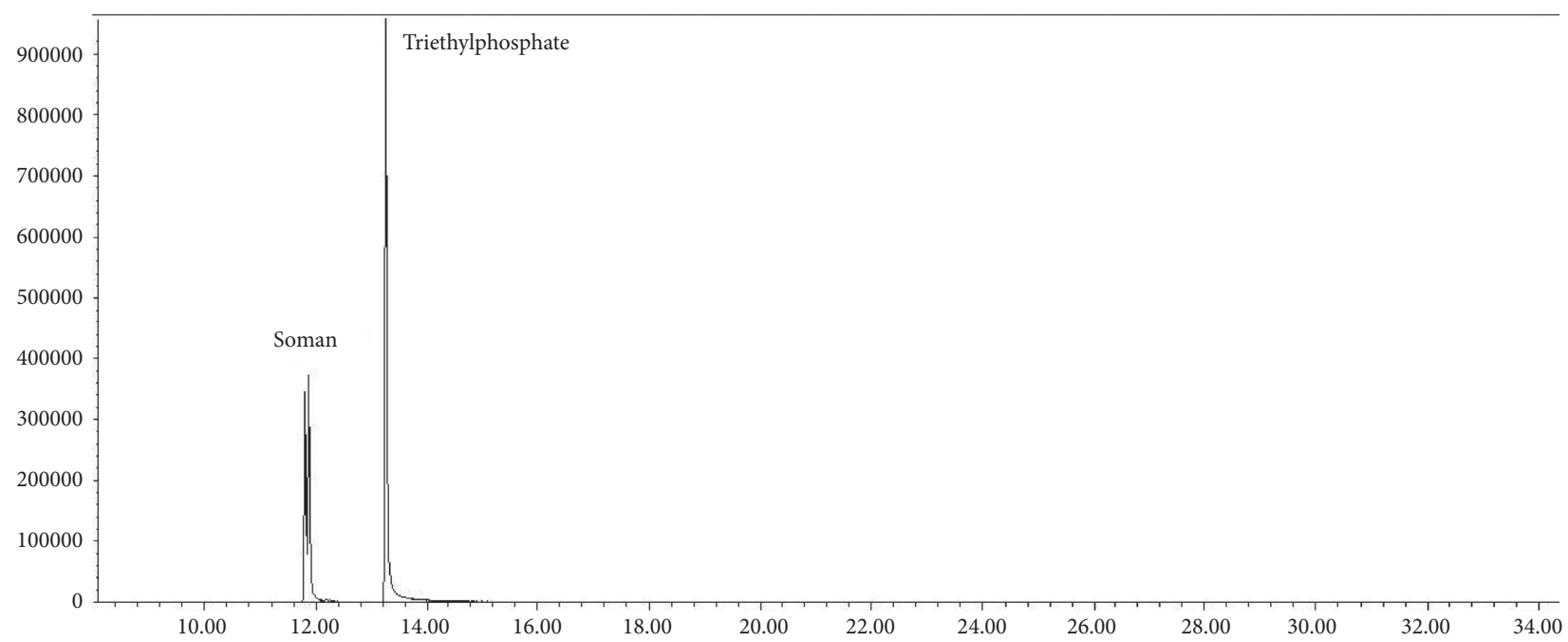

(a)

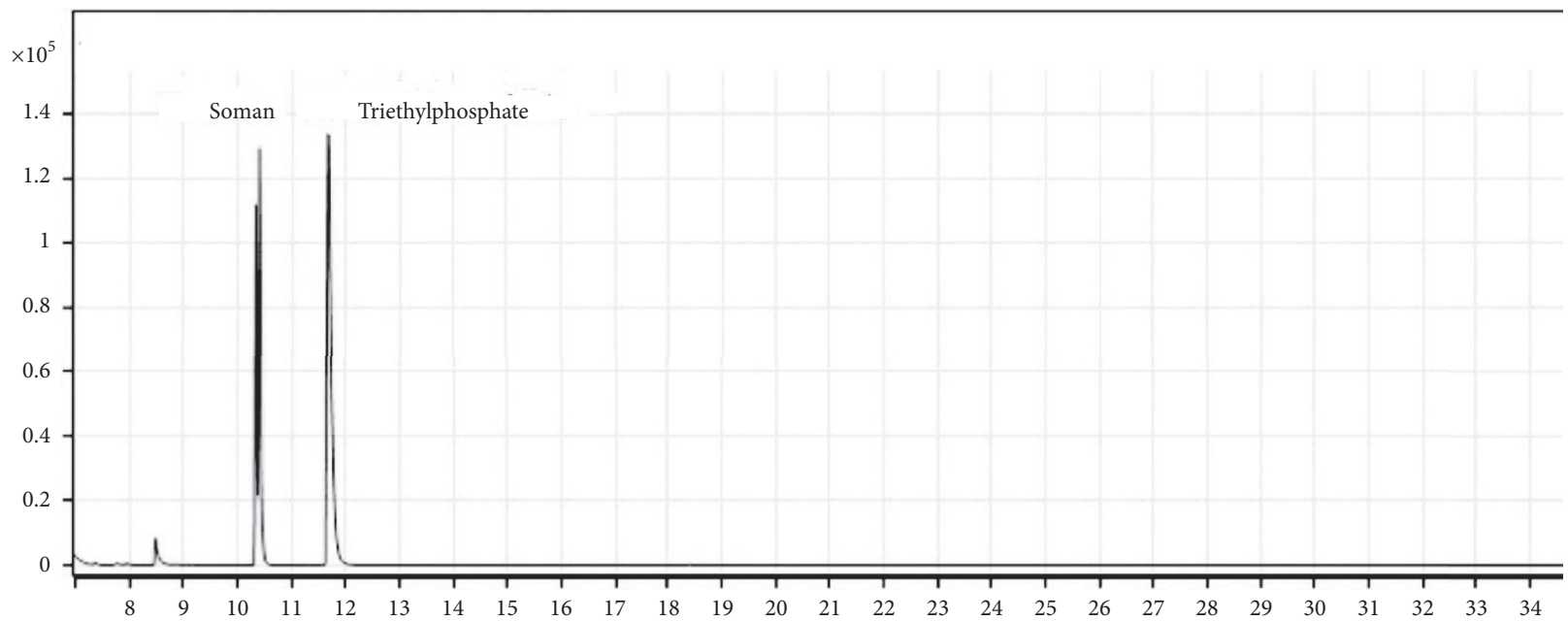

(b)

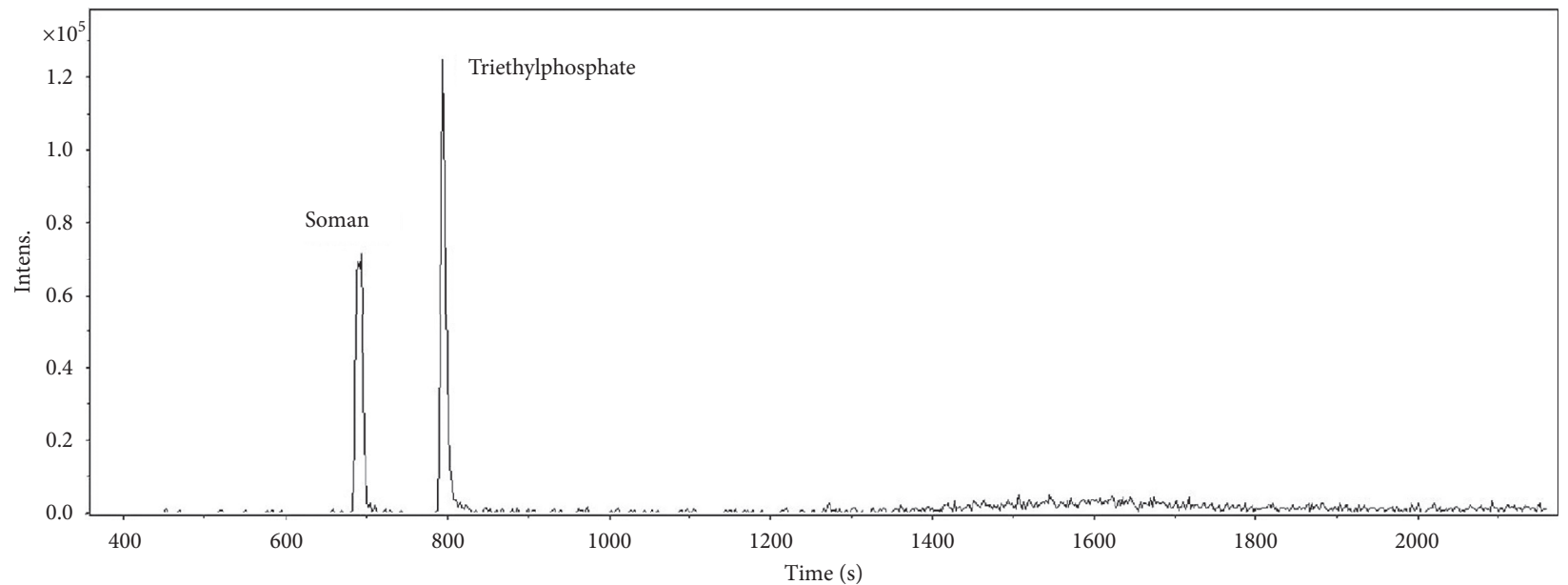

(c)

Figure 2: Examples of soman and triethylphosphate chromatograms extracted at $m / z 99$ measured on the following GC/MS systems: (a) $7890 \mathrm{~A} / 5975 \mathrm{C}, \mathbf{c}_{\mathrm{CWA}}=10.7 \mathrm{mg} / \mathrm{L}, \mathbf{c}_{\mathrm{ISTD}}=15.3 \mathrm{mg} / \mathrm{L}$, (b) intuvo $9000 / 5977 \mathrm{~B}, \mathbf{c}_{\mathrm{CWA}}=7.3 \mathrm{mg} / \mathrm{L}, \mathbf{c}_{\mathrm{ISTD}}=4.3 \mathrm{mg} / \mathrm{L}$, and (c) EM 640 , $\mathbf{c}_{\mathrm{CWA}}=39.0 \mathrm{mg} / \mathrm{L}, \mathbf{c}_{\mathrm{ISTD}}=31.9 \mathrm{mg} / \mathrm{L}$. 
TABLE 6: Evaluation of the chromatographic peak area of the VX agent and di-n-hexylamine at $m / z 114$ as a linear function of their concentration (critical values of the correlation coefficient $\mathbf{R}_{\mathrm{CRIT}} 0.99$ and QC coefficient $\mathrm{QC}_{\mathrm{CRIT}} 5.00$ ).

\begin{tabular}{|c|c|c|c|c|c|c|}
\hline \multirow{2}{*}{ GC/MS compound } & \multicolumn{2}{|c|}{$7890 \mathrm{~A} / 5975 \mathrm{C}$} & \multicolumn{2}{|c|}{ Intuvo $9000 / 5977 \mathrm{~B}$} & \multicolumn{2}{|c|}{ EM 640} \\
\hline & VX & Dihexyl-amine & vX & Dihexyl-amine & VX & Dihexyl-amine \\
\hline Retention time (min) & 22.1 & 17.0 & 18.6 & 14.4 & 23.8 & 17.7 \\
\hline Linearity range $(\mathrm{mg} / \mathrm{L})$ & $7.5-20$ & $7.5-20$ & $7.5-20$ & $7.5-20$ & $15-50$ & $15-50$ \\
\hline $\mathbf{R}$ & 0.9934 & 0.9981 & 0.9987 & 0.9938 & 0.9999 & 0.9999 \\
\hline $\mathrm{QC}$ & 4.38 & 4.81 & 4.68 & 3.89 & 0.43 & 0.23 \\
\hline Gradient $\left(A \times 10^{-6} \times \mathrm{L} / \mathrm{mg}\right)$ & 0.38 & 0.67 & 0.24 & 0.45 & 0.020 & 0.036 \\
\hline Intercept $\left(A \times 10^{-6}\right)$ & -0.21 & -0.49 & -0.031 & 0.033 & 0.0013 & -0.0023 \\
\hline $\begin{array}{l}\text { Response factor } F_{R} \\
\text { Average value of } F_{R}\end{array}$ & \multicolumn{2}{|c|}{0.57} & \multicolumn{2}{|c|}{$\begin{array}{l}0.54 \\
0.55\end{array}$} & \multicolumn{2}{|c|}{0.55} \\
\hline
\end{tabular}

TABLE 7: Evaluation of the chromatographic peak area of edemo and tri-n-butylphosphate at $\mathrm{m} / z$ 99 as a linear function of their concentration (critical values of the correlation coefficient $\mathbf{R}_{\text {CRIT }} 0.99$ and QC coefficient QC CRIT 5.00 ).

\begin{tabular}{lcccccc}
\hline \multirow{2}{*}{ GC/MS compound } & \multicolumn{2}{c}{$7890 \mathrm{~A} / 5975 \mathrm{C}$} & \multicolumn{2}{c}{ Intuvo 9000/5977B } & \multicolumn{2}{c}{ EM 640 } \\
& Edemo & Tributyl-phosphate & Edemo & Tributyl-phosphate & Edemo & Tributyl-phosphate \\
\hline Retention time $(\mathrm{min})$ & 20.5 & 21.2 & 16.4 & 17.1 & 18.9 & 19.6 \\
Linearity range $(\mathrm{mg} / \mathrm{L})$ & $5-30$ & $5-30$ & $2.5-15$ & $2.5-12.5$ & $10-50$ & $10-50$ \\
$\mathbf{R}$ & 0.9964 & 0.9996 & 0.9980 & 0.9967 & 0.9978 & 0.9981 \\
QC & 4.00 & 2.14 & 4.62 & 4.53 & 3.29 & 0.014 \\
Gradient $\left(A \times 10^{-6} \times \mathrm{L} / \mathrm{mg}\right)$ & 1.1 & 4.2 & 0.16 & 0.61 & 0.0017 & 0.0045 \\
Intercept $\left(A \times 10^{-6}\right)$ & -0.18 & -2.1 & -0.012 & -0.11 & 0.27 & \\
Response factor $\mathbf{F}_{\mathbf{R}}$ & & 0.25 & & & 0.26 & \\
Average value of $\mathbf{F}_{\mathbf{R}}$ & & & & & & \\
\hline
\end{tabular}

TABLE 8: Evaluation of the chromatographic peak area of Medemo and di-n-amylether at $m / z 71$ as a linear function of their concentration (critical values of the correlation coefficient $\mathbf{R}_{\text {CRIT }} 0.99$ and QC coefficient QC CRIT 5.00).

\begin{tabular}{|c|c|c|c|c|c|c|}
\hline \multirow{2}{*}{ GC/MS compound } & \multicolumn{2}{|c|}{$7890 \mathrm{~A} / 5975 \mathrm{C}$} & \multicolumn{2}{|c|}{ Intuvo $9000 / 5977 \mathrm{~B}$} & \multicolumn{2}{|c|}{ EM 640} \\
\hline & Medemo & Diamyl-ether & Medemo & Diamyl-ether & Medemo & Diamyl-ether \\
\hline Retention time (min) & 18.4 & 12.4 & 14.6 & 9.5 & 19.2 & 13.2 \\
\hline Linearity range $(\mathrm{mg} / \mathrm{L})$ & $10-40$ & $5-40$ & $2.5-12$ & $2.5-12$ & $15-50$ & $10-50$ \\
\hline $\mathbf{R}$ & 0.9988 & 0.9997 & 0.9997 & 0.9968 & 0.9995 & 0.9998 \\
\hline QC & 2.58 & 1.77 & 0.81 & 4.01 & 1.68 & 0.79 \\
\hline Gradient $\left(A \times 10^{-6} \times \mathrm{L} / \mathrm{mg}\right)$ & 0.53 & 2.5 & 0.11 & 0.49 & 0.017 & 0.084 \\
\hline Intercept $\left(A \times 10^{-6}\right)$ & -0.10 & -1.3 & -0.014 & -0.0034 & -0.0089 & -0.00095 \\
\hline $\begin{array}{l}\text { Response factor } \mathbf{F}_{\mathbf{R}} \\
\text { Average value of } \mathbf{F}_{R}\end{array}$ & \multicolumn{2}{|c|}{0.21} & \multicolumn{2}{|c|}{$\begin{array}{l}0.22 \\
0.21\end{array}$} & \multicolumn{2}{|c|}{0.20} \\
\hline
\end{tabular}

Precision was statistically assessed by the method of concentration levels from parallel measurements and calculation of relative standard deviations [37]. Precision was evaluated for the abovementioned sets of five results.

The accuracy and precision assessment are summarized in Table 9, indicating that the method yields accurate results and that the relative standard deviation does not exceed $15 \%$ which generally corresponds to the precision of GC/MC-based determination procedures. The highest values of relative repeatability were achieved on the EM 640 system. On the 7890A/ 5975C and Intuvo 9000/5977B GC/MS systems, the maximum relative precision of CWAs determination reached $7 \%$.

3.8. Multilaboratory Comparison. The studied determination method could also be verified in a multilaboratory comparison performed as part of the FRS chemical laboratories proficiency testing. The investigation was performed in
2017-2019 with six chemical laboratories equipped with three 7890A/5975C GC/MS systems, five Intuvo 9000/5977B systems, and two mobile EM 640 systems. Accuracy of the results was evaluated by statistical software [37]. The value of the $z$ score as a ratio of the difference of known and determined concentration and standard deviation was calculated. Results with an absolute value of $z$-score below or equal to 2.0 were considered as accurate. A relative standard deviation of $12.5 \%$ was chosen for the calculation of the $z$ value.

Evaluation of the multilaboratory comparison is summarized in Table 10. In total, $3.1 \%$ of inaccurate results were obtained during the analysis of five CWAs. The relative difference of known and determined concentration between the laboratories did not exceed 6\%. Taking into account that participants of the multilaboratory comparison did not have standards of the nerve-paralysing agents available, these results can be considered very good. 
TABLE 9: Assessment of CWA determination accuracy and precision testing ( $\mathbf{c}_{\mathrm{ISTD}}$-internal standard concentration, $t-t$ criterion value, $S_{R}$-relative standard deviation, number of measurements $n=5$, and $t_{\mathrm{CRIT}}=2.776$ ).

\begin{tabular}{|c|c|c|c|c|c|c|}
\hline CWA/Internal standard & $\begin{array}{c}\mathbf{c}_{\text {ISTD }} \\
(\mathrm{mg} / \mathrm{L}) \\
\end{array}$ & $\begin{array}{c}\text { Known CWA concentration } \\
(\mathrm{mg} / \mathrm{L})\end{array}$ & GC/MS system & $\begin{array}{c}\text { Determined concentration } \\
(\mathrm{mg} / \mathrm{L})\end{array}$ & $t$ & $\begin{array}{c}S_{R} \\
(\%) \\
\end{array}$ \\
\hline \multirow{3}{*}{ Tabun/heptan-1-ol } & \multirow{2}{*}{30.0} & \multirow{2}{*}{32.7} & $7890 \mathrm{~A} / 5975 \mathrm{C}$ & 29.9 & 2.147 & 4.0 \\
\hline & & & EM 640 & 31.6 & 1.152 & 11.1 \\
\hline & 4.0 & 3.4 & $\begin{array}{c}\text { Intuvo 9000/ } \\
5977 \mathrm{~B}\end{array}$ & 3.6 & 1.263 & 2.2 \\
\hline \multirow{3}{*}{ Sarin/triethyl-phosphate } & \multirow{2}{*}{20.0} & \multirow{2}{*}{14.5} & $7890 \mathrm{~A} / 5975 \mathrm{C}$ & 14.5 & 0.049 & 3.8 \\
\hline & & & EM 640 & 13.3 & 1.792 & 14.7 \\
\hline & 5.0 & 9.1 & $\begin{array}{c}\text { Intuvo 9000/ } \\
5977 \mathrm{~B}\end{array}$ & 9.7 & 2.046 & 6.0 \\
\hline \multirow{5}{*}{ Soman/triethyl-phosphate } & \multirow[t]{2}{*}{20.0} & \multirow[t]{2}{*}{19.5} & $7890 \mathrm{~A} / 5975 \mathrm{C}$ & 18.3 & 0.311 & 5.6 \\
\hline & & & EM 640 & 19.0 & 0.745 & 4.2 \\
\hline & \multirow[t]{3}{*}{12.0} & \multirow[t]{3}{*}{7.0} & $7890 \mathrm{~A} / 5975 \mathrm{C}$ & 7.5 & 1.538 & 5.4 \\
\hline & & & $\begin{array}{c}\text { Intuvo 9000/ } \\
5977 \mathrm{~B}\end{array}$ & 6.7 & 1.147 & 3.7 \\
\hline & & & EM 640 & 7.1 & 0.297 & 9.3 \\
\hline \multirow{6}{*}{$\begin{array}{l}\text { Cyclosarin/triethyl- } \\
\text { phosphate }\end{array}$} & \multirow[t]{2}{*}{25.0} & \multirow[t]{2}{*}{21.0} & $7890 \mathrm{~A} / 5975 \mathrm{C}$ & 20.3 & 0.459 & 5.6 \\
\hline & & & EM 640 & 20.7 & 0.612 & 4.2 \\
\hline & \multirow[t]{3}{*}{12.0} & \multirow[t]{3}{*}{8.8} & 7890A/5975C & 9.5 & 2.005 & 5.4 \\
\hline & & & $\begin{array}{c}\text { Intuvo 9000/ } \\
5977 \mathrm{~B}\end{array}$ & 7.9 & 1.916 & 3.7 \\
\hline & & & EM 640 & 8.9 & 0.309 & 9.3 \\
\hline & 5.0 & 3.7 & $\begin{array}{c}\text { Intuvo 9000/ } \\
5977 \mathrm{~B}\end{array}$ & 4.0 & 1.714 & 6.0 \\
\hline \multirow{5}{*}{$\begin{array}{l}\text { VX agent/di-n- } \\
\text { hexylamine }\end{array}$} & \multirow[t]{2}{*}{15.0} & \multirow[t]{2}{*}{17.7} & $7890 \mathrm{~A} / 5975 \mathrm{C}$ & 17.0 & 0.699 & 5.6 \\
\hline & & & $\begin{array}{c}\text { Intuvo 9000/ } \\
5977 \mathrm{~B}\end{array}$ & 16.7 & 1.015 & 4.9 \\
\hline & \multirow{3}{*}{10.0} & \multirow{3}{*}{19.3} & EM 640 & 15.3 & 1.973 & 8.4 \\
\hline & & & $7890 \mathrm{~A} / 5975 \mathrm{C}$ & 17.6 & 1.514 & 6.8 \\
\hline & & & $\begin{array}{c}\text { Intuvo 9000/ } \\
\text { 5977B } \\
\end{array}$ & 18.0 & 1.865 & 9.0 \\
\hline \multirow{5}{*}{$\begin{array}{l}\text { Edemo/tri-n- } \\
\text { butylphosphate }\end{array}$} & \multirow[t]{2}{*}{10.0} & \multirow[t]{2}{*}{11.0} & $7890 \mathrm{~A} / 5975 \mathrm{C}$ & 10.3 & 1.052 & 7.4 \\
\hline & & & $\begin{array}{c}\text { Intuvo 9000/ } \\
5977 \mathrm{~B}\end{array}$ & 11.2 & 0.328 & 3.9 \\
\hline & \multirow[t]{2}{*}{27.0} & \multirow[t]{2}{*}{22.2} & $7890 \mathrm{~A} / 5975 \mathrm{C}$ & 23.6 & 0.874 & 5.8 \\
\hline & & & EM 640 & 22.3 & 0.079 & 6.5 \\
\hline & 8.0 & 6.1 & $\begin{array}{c}\text { Intuvo 9000/ } \\
5977 \mathrm{~B}\end{array}$ & 5.9 & 1.232 & 6.6 \\
\hline \multirow{3}{*}{ Medemo/di-n-amylether } & \multirow[t]{2}{*}{40.0} & \multirow[t]{2}{*}{35.0} & $7890 \mathrm{~A} / 5975 \mathrm{C}$ & 35.8 & 1.051 & 4.8 \\
\hline & & & EM 640 & 36.2 & 0.782 & 12.3 \\
\hline & 10.0 & 6.5 & $\begin{array}{c}\text { Intuvo 9000/ } \\
5977 \mathrm{~B}\end{array}$ & 6.9 & 0.429 & 5.1 \\
\hline
\end{tabular}

TABLE 10: Evaluation of multilaboratory comparison results, showing the determination of several CWAs using the GC/method with the internal standard procedure.

\begin{tabular}{|c|c|c|c|c|c|c|}
\hline \multicolumn{2}{|l|}{ Compound } & Tabun & Sarin & Soman & VX agent & Edemo \\
\hline \multicolumn{2}{|l|}{ Known concentration $(\mathrm{mg} / \mathrm{L})$} & 7.5 & 9.9 & 15.0 & 18.7 & 23.5 \\
\hline \multicolumn{2}{|l|}{ Total number of results } & 16 & 24 & 18 & 20 & 20 \\
\hline \multirow[t]{3}{*}{ Accurate/inaccurate results obtained on the system } & $7890 \mathrm{~A} / 5975 \mathrm{C}$ & $6 / 0$ & $9 / 0$ & $8 / 0$ & $6 / 0$ & $8 / 0$ \\
\hline & Intuvo $9000 / 5977 \mathrm{~B}$ & $10 / 0$ & $8 / 1$ & $6 / 0$ & $8 / 1$ & $6 / 0$ \\
\hline & EM 640 & $0 / 0$ & $6 / 0$ & $4 / 0$ & $4 / 1$ & $6 / 0$ \\
\hline \multicolumn{2}{|l|}{ Total number of accurate results } & 16 & 23 & 18 & 18 & 20 \\
\hline \multicolumn{2}{|c|}{ Average determined multilaboratory concentration $(\mathrm{mg} / \mathrm{L})$} & 7.2 & 9.7 & 14.3 & 19.7 & 24.8 \\
\hline \multicolumn{2}{|c|}{ Relative difference of known and determined concentration (\%) } & -4.0 & -2.0 & -4.7 & +5.3 & +5.5 \\
\hline \multicolumn{2}{|l|}{ Relative standard deviation between laboratories (\%) } & 10.0 & 14.1 & 9.7 & 13.3 & 14.4 \\
\hline
\end{tabular}




\section{Conclusions}

A procedure based on the use of an internal standard in GC/ MS analysis was developed to determine the concentration of nerve agents. We found that determination of response factors from TIC chromatograms recorded in the scan mode is not suitable. A standard which would have an identical response factor across the systems tested could only be identified in exceptional cases; in fact, the response factor values highly differed in most cases. An optimal procedure was to use the EIC chromatogram extracted for a particular ion, extracting both CWA and internal standard peaks at the same $\mathrm{m} / z$ ratio. Unlike TIC chromatograms, the EIC chromatograms exhibit linearity of the chromatographic peak area function of concentration in a much wider range, and the peak area readings are significantly more reproducible and robust against interference with compounds with close retention times.

We were able to identify and verify a standard which exhibits a pronounced peak corresponding to the same ion present in the CWA mass spectrum, and verified the useful concentration range for all nerve agents in scope of this work. The response factors for individual CWAs and internal standards were calculated as ratios of the gradient of linear functions of the peak area and concentration. The response factors are valid across all GC/MS systems within the FRS laboratories. A simple procedure for the determination, comprising the preparation of CWA and internal standard solutions, their mixing, and injection into the GC/ MS system, was developed. The analysis is followed by identification of the components as usual, extraction of the chromatogram at a particular $\mathrm{m} / \mathrm{z}$ value, integration, and reading of the chromatographic peak area of the analyte and the internal standard. The CWA concentration is, then, calculated based on the internal standard concentration, peak areas, and response factor.

The determination procedure was validated by accuracy and repeatability testing and by multilaboratory comparison. The validation showed that the procedure yields accurate results, and the relative standard deviation does not exceed $15 \%$ which corresponds to the precision of GC/MS-based determinations. During the multilaboratory comparison, only 3 out of 98 results of the five CWAs analysed were found inaccurate. The relative difference of known concentrations and concentration determined in the different participating laboratories did not exceed $6 \%$.

The most important and decisive asset of this work is that the developed procedure enables the chemical laboratories to determine the concentration of CWAs in a solution in the absence of standards. This is especially important for the determination of purity of own CWA preparates which are, then, in turn used for the preparation of calibration solutions for other methods employed.

\section{Data Availability}

No data were used to support this study.

\section{Conflicts of Interest}

The authors declare that there are no conflicts of interest regarding the publication of this paper.

\section{Acknowledgments}

This study was supported by the Ministry of Interior of the Czech Republic (Security Research and Development Project no. VI20152020009).

\section{References}

[1] I. G. Zenkevich, E. D. Makarov, and I. Y. Makarova, "Quantitative chromatographic analysis under changes in the composition of samples in the course of sample preparation: a modification of the double internal standard method," Journal of Analytical Chemistry, vol. 62, no. 8, pp. 748-755, 2007.

[2] T. E. Siebert, C. Wood, G. M. Elsey, and A. P. Pollnitz, "Determination of rotundone, the pepper aroma impact compound, in grapes and wine," Journal of Agricultural and Food Chemistry, vol. 56, no. 10, pp. 3745-3748, 2008.

[3] I. G. Zenkevich, A. Y. Eshchenko, and I. O. Klimova, "Characterization of the interlaboratory reproducibility of results in quantitative gas-chromatographic analysis using the internal normalization method," Journal of Analytical Chemistry, vol. 60, no. 2, pp. 119-124, 2005.

[4] B.-G. Chen, C. D. Chang, C.-T. Wang et al., "A novel approach to evaluate the extent and the effect of cross-contribution to the intensity of ions designating the analyte and the internal standard in quantitative GC-MS analysis," Journal of the American Society for Mass Spectrometry, vol. 19, no. 4, pp. 598-608, 2008.

[5] A. C. Soria, I. Martínez-Castro, and J. Sanz, "Some aspects of dynamic headspace analysis of volatile components in honey," Food Research International, vol. 41, no. 8, pp. 838-848, 2008.

[6] C. K. Van Pelt, P. Haggarty, and J. T. Brenna, "Quantitative subfemtomole analysis of $\alpha$-tocopherol and deuterated isotopomers in plasma using tabletop GC/MS/MS," Analytical Chemistry, vol. 70, no. 20, pp. 4369-4375, 1998.

[7] J. J. Langenfeld, S. B. Hawthorne, and D. J. Miller, "Quantitative analysis of fuel-related hydrocarbons in surface water and wastewater samples by solid-phase microextraction," Analytical Chemistry, vol. 68, no. 1, pp. 144-155, 1996.

[8] T. Iwai, K. Kakegawa, M. Aida et al., "Development of a gascylinder-free plasma desorption/ionization system for on-site detection of chemical warfare agents," Analytical Chemistry, vol. 87, no. 11, pp. 5707-5715, 2015.

[9] P. Wu, L. Zhang, X. Shen et al., "Determination of ethyl carbamate in Chinese yellow rice wine by diatomaceous earth extraction and GC/MS method," Journal of AOAC International, vol. 98, no. 3, pp. 79-82, 2015.

[10] E. Waś, T. Szczesna, and H. Rybak-Chmielewska, "Application of gas chromatography with the mass detector (GC-MS) technique for detection of beeswax adulteration with paraffin," Journal of Apicultural Science, vol. 59, no. 1, pp. 143-152, 2015.

[11] S. Nicoara, L. Toninandel, P. Traldi et al., "Determining the levels of volatile organic pollutants in urban air using a gas chromatography-mass spectrometry method," Journal of Environmental and Public Health, vol. 2019, 4 pages, 2009.

[12] F. Smith, M. Augsburger, and V. Varlet, "Accuracy profile validation of a new analytical method for propane 
measurement using headspace-gas chromatography-mass spectrometry," Journal of Analytical Toxicology, vol. 38, no. 2, pp. 73-79, 2014.

[13] D. Downey, K. Simons, K. Ota, and S. Kerrigan, "Quantitative analysis of carisoprodol and meprobamate in whole blood using benzylcarbamate and deuterated meprobamate as internal standards quantitative analysis of carisoprodol and meprobamate in whole blood using benzylcarbamate and deuterated meprobamate as internal standards," Journal of Analytical Toxicology, vol. 33, no. 5, pp. 278-282, 2009.

[14] D. Méndez, P. G. Gonzales, A. E. Botello et al., "Solid-phase microextraction of n-nitrosodimethylamine in beer," Food Chemistry, vol. 107, no. 3, pp. 1348-1352, 2008.

[15] B. Lazarov, R. Swinnen, M. Spruyt et al., "Air sampling of flame retardants based on the use of mixed-bed sorption tubes-a validation study," Environmental Science and Pollution Research, vol. 22, no. 22, pp. 18221-18229, 2015.

[16] N. J. Martin, P. A. Smith, C. W. Brown, N. L. Achee, and G. T. Delong, "Dichlorodiphenyl trichloro ethane determination in air by thermal desorption gas chromatography-mass spectrometry," Pest Management Science, vol. 68, no. 10, pp. 1360-1367, 2012.

[17] D. G. Burke and L. G. Mackay, "Complete equation for the measurement of organic molecules using stable isotope labeled internal standards, exact matching, and mass spectrometry," Analytical Chemistry, vol. 80, no. 13, pp. 5071-5078, 2008.

[18] A. F. Lagalante and M. A. Felter, "Silylation of acrylamide for analysis by solid-phase microextraction/gas chromatography/ ion-trap mass spectrometry," Journal of Agricultural and Food Chemistry, vol. 52, no. 12, pp. 3744-3748, 2004.

[19] S. M. Hankin, P. John, A. W. Simpson, and G. P. Smith, "Spatially resolved time-of-flight mass spectrometry of polycyclic aromatic hydrocarbons: quantification studies," Analytical Chemistry, vol. 68, no. 18, pp. 3238-3243, 1996.

[20] M. Li, T.-G. Wang, B. R. T. Simoneit, S. Shi, L. Zhang, and F. Yang, "Qualitative and quantitative analysis of dibenzothiophene, its methylated homologues, and benzonaphthothiophenes in crude oils, coal, and sediment extractsquantitative analysis of dibenzothiophene, its methylated homologues, and benzonaphthothiophenes in crude oils, coal, and sediment extracts," Journal of Chromatography A, vol. 1233, pp. 126-136, 2012.

[21] J. Wu, N. Lam, D. Martens, A. Kettrup, and Z. Cai, "Triclosan determination in water related to wastewater treatment," Talanta, vol. 72, no. 5, pp. 1650-1654, 2007.

[22] C. Walgraeve, K. Demeestere, J. Dewulf, K. Van Huffel, and H. Van Langenhove, "Diffusive sampling of 25 volatile organic compounds in indoor air: uptake rate determination and application in flemish homes for the elderly," Atmospheric Environment, vol. 45, no. 32, pp. 5828-5836, 2011.

[23] H. D. Duc, H. Van Longenhove, S. Izukuchwu Chigbo et al., "Exposure to volatile organic compounds: comparison among different transportation modes," Atmospheric Environment, vol. 94, pp. 53-62, 2014.

[24] M. Tobiszevski and J. Namieśnik, "Determination of chlorinated solvents in industrial water and wastewater by DAI-GCECD," Analytical and Bioanalytical Chemistry, vol. 399, no. 10, pp. 3565-3572, 2011.

[25] C. Raepel, M. Fabritius, M. Nief et al., "Analysis of airborne pesticides from different chemical classes adsorbed on radiello $^{\circledR}$ tenax ${ }^{\circledR}$ passive tubes by thermal-desorption-GC/MS," Environmental Science and Pollution Research, vol. 22, no. 4, pp. 2726-2734, 2015.
[26] A. E. Witter, "The quantitative determination of butylated hydroxytoluene in chewing gum using GC-MS," Journal of Chemical Education, vol. 82, no. 10, p. 1538, 2005.

[27] R. G. Buttery, G. R. Takeoka, M. Naim, H. Rabinowitch, and Y. Nam, "Analysis of furaneol in tomato using dynamic headspace sampling with sodium sulfate," Journal of Agricultural and Food Chemistry, vol. 49, no. 9, pp. 4349-4351, 2001.

[28] B. I. Brookes, "Gas analysis using an internal standard in adsorption tubes," The Analyst, vol. 104, no. 1240, pp. 698-699, 1979.

[29] M.-F. Wang, H.-Z. Lian, L. Mao et al., "Comparison of various extraction methods for policosanol from rice bran wax and establishment of chromatographic fingerprint of policosanol," Journal of Agricultural and Food Chemistry, vol. 55, no. 14, pp. 5552-5558, 2007.

[30] S. A. Vekiari, E. E. Protopapadakis, P. Papadopoulou, D. Papanicolaou, C. Panou, and M. Vamvakias, "Composition and seasonal variation of the essential oil from leaves and peel of a cretan lemon variety," Journal of Agricultural and Food Chemistry, vol. 50, no. 1, pp. 147-153, 2002.

[31] N. Innocente, S. Corradini, and L. S. Conte, "A rapid method for the quantitative determination of short-chain free volatile fatty acids from cheese," Journal of Agricultural and Food Chemistry, vol. 48, no. 8, pp. 3321-3323, 2000.

[32] S. R. Huang and P. T. Palmer, "Improving student understanding of qualitative and quantitative analysis via GC/MS using a rapid spme-based method for determination of trihalomethanes in drinking water," Journal of Chemical Education, vol. 94, no. 8, pp. 1129-1132, 2017.

[33] H.-C. Liu, W. Den, S.-F. Chan, and K. T. Kin, "Analysis of trace contamination of phthalate esters in ultrapure water using a modified solid-phase extraction procedure and automated thermal desorption-gas chromatography/mass spectrometry," Journal of Chromatography A, vol. 1188, no. 2, pp. 286-294, 2008.

[34] X. Bian, L. Feng, G. Li, Z. Chen, and X. Chen, "Quantification of residual monomer in polylactide by gas chromatographic internal standard methodinternal standard method," Polymer Testing, vol. 50, pp. 79-82, 2016.

[35] G. Beltran, M. P. Aguilera, and M. H. Gordon, "Solid phase microextraction of volatile oxidation compounds in oil-in-water emulsions," Food Chemistry, vol. 92, no. 3, pp. 401-406, 2005.

[36] M. C. Koning, Decontamination of Cwas by Hvezda-A Summary of Results, Earth Environmental and Life Sciences, Rijswijk, Netherlands, 2013.

[37] Oulehla, Statistical Software EffiValidation: Version 3.0-EffiChem, Oulehla, Štěpánov, Czech Republic, 2002.

[38] M. J. Van Der Schans, "Laboratory analysis of chemical warfare agents and metabolites in biomedical samples," in Handbook of Toxicology Chemical Warfare Agents, R. C. Gupta, Ed., pp. 827-835, Academic Press Elsevier, London, UK, 1st edition, 2009.

[39] C. Walgraeve, K. Demeestere, J. Dewulf, K. Van Huffel, and H. Van Langenhove, "Uptake rate behavior of tube-type passive samplers for volatile organic compounds under controlled atmospheric conditionstube-type passive samplers for volatile organic compounds under controlled atmospheric conditions," Atmospheric Environment, vol. 45, no. 32, pp. 5872-5879, 2011.

[40] A. C. Soria, I. Martínez-Castro, and J. Sanz, "Study of the precision in the purge-and-trap-gas chromatography-mass spectrometry analysis of volatile compounds in honey," Journal of Chromatography A, vol. 1216, no. 15, pp. 33003304, 2009. 